The Third Pole: Journal of Geography

Vol. 18 - 19: 11-20, 2019

DOI: https://doi.org/10.3126/ttp.v18i0.27990

Department of Geography Education,

Central Department of Education, T.U., Kathmandu, Nepal

\title{
BID-RENT THEORY AND URBAN LAND USE OF BUTWAL URBAN AREA, WESTERN NEPAL
}

\begin{abstract}
Modern urbanization process characterizes different land use pattern than that of classical urban land use theories. However, the general scenario of land use pattern still related to classical theories. Thus, this paper aims to assess the application of classical land use model and land economic theory in Butwal urban area of western Nepal based on field study information collected from 50 randomly selected plots of the Butwal urban area. Thematic maps of various urban land features were prepared, and regression analyses have been used. Geographic Information System (GIS), excel and Statistical Packages for Social Sciences (SPSS) software were used for data analysis. The findings of this study indicate that classical model has important role to study medium size urban land use. Simultaneously, land economic theory is also equally applicable with considering the physical and social factors of land use for urban area.
\end{abstract}

Chhabi Lal Chidi ${ }^{1}$

Key words: Bid-rent, urban land use, rent gradient, economic model transportation cost.

\section{Introduction}

Recent development and urbanization process in African countries shows the classical land use theories have important role to study urban area land use to be considered according in recent times (Ngidi, 2016). The analysis of the effect of transportation on land use involves the fundamental concept in urban economy that was introduced by Alonso (1964) - bid rents. Patterns of urban land use determined by land values related to transportation costs. Each urban activity has own bid rent function and the combination of several bid rent functions as the rent gradient. Higher accessibility of an urban site to desirable destinations increases the rent that is offered for that site. The urban economy is made up of different sectors such as households, businesses, industries, and governmental entities (Putman, 1975). This bid-rent theory is defined

1 Chidi is a Lecturer, Central Department of Geography, Tribhuvan University, Kathmandu Nepal,Email: chidichhabilal@gmail.com 
as the maximum amount that households or firms are willing to offer for a unit of land, given a level of services or benefits. All have their own hypothetical bid rent for each urban site. If the land market is permitted to function so that the highest bidder occupies the site, then both the allocation of the land to a particular use and the intensity of that use are determined by the market (McDonald, 2006). The retailer is willing to pay high rent for a site near the central business district (CBD) where accessibility is prime importance, but is unwilling to pay much for sites more than about 500 meters from the peak land-value interaction, because the distance shoppers are willing to walk in short (Samli, 1998). The curve for industry starts low because the manufacturer cannot afford the high rents that a retailer can but drops away less sharply because pedestrian access is not such a key point. Similarly, residential gradient drops even less sharply than industry (Mayhew, 2006). Thus bid-rent theory gives emphasis on the direct relation between transport cost and land use intensity which is not exactly applicable in all urban spatial pattern. Other aspects like physical, resources, accessibility, multiple service centers are the determining factor of urban land use. So, the exact concentric pattern is rarely found.

Bid rent theory does not directly lead to an operational model for land use and land prices. It relies strongly on an analysis of the market, market prices and bids actors which are valuable information for sustainable land use planning and management. In case of Nepal very few urban land use studies are found with very little information about urban land use as well, however; Nepal is known as top ten fastest urbanizing countries in the world (Bakrania, 2015). Therefore, it is inevitable to have the up to date information of urban activities and land use. However, there are few studies in Nepal and government has no adequate assessment. The main aim of this paper is to identify the urban activities in medium size towns and their patterns according to bit rent function or contribution to information gap and helpful for further research and guidance for urban planning.

\section{Materials and Methods}

Data sources: This study is mainly based on primary data source. Topographic maps and Google images have been used to collect field information and map preparation work. The large parts of sub-municipal area in rural in nature; therefore, this study executed only in the built-up area of Butwal which accounts 15.2 square kilometers having eastwest length $4.8 \mathrm{~km}$ and north-south 5.6 kilometers. Preliminary observation, sampled plot selection, and site identification were done with the help of Google image and topographic maps. Fifty locations were selected randomly to derive field data to have more than 30 observations for statistical analysis. Selected locations were distinct aerial units delineated into patch separated by streets, fences, and other natural barriers. The 
selected average patch size was 0.81 hectares having the smallest patch size was 0.20 hectares and the largest was 2.71 hectares. Those sampled plots were used to collect detailed information on land value and land use.

Travel distance from CBD (cost and time), land value, room rent, and building storey information were collected from same selected plots. Uses of rooms for various purposes such as business, industry, institutional and residential information were collected through focus group discussion (FGD) method with local people using FGD guideline. As concerning with spatial variation, all primary and secondary data were processed accordingly. Distances, travel time and travel costs of the individual sampled plot were tabulated. Average land value, room rent, building storey were calculated. Total units of various functions such as business, industry, institution and residential per hectare area were calculated. Table of distances from the CBD, highway distance, travel distance, land value, room rent, building storey, marketing units, industrial units, and residential units per hectare of land, and urban functional units (marketing, industrial and institutional units) were derived. Maps of separate themes have been prepared compiling with topographic features. Distance from CBD, marketing unit, industrial unit and residential unit data were standardized to identify the comparative variance ratio. Scatter plot and regression line of market types, industrial and residential units with distance from CBD were prepared to identify the applicability of bid rent theory in Butwal Municipality.

Study area: Butwal Municipality of Rupandehi district Province 5 of federal Nepal has selected to the study area. It is located at the foothill of Siwalik range. Northern side of this municipality is steep hillsides of Siwalik. It is located at the intersection of Nepal's two important national highways, i.e. East-west Highway (Mahendra) and Siddhartha Highway which connect western Nepal and the capital city Kathmandu. Siddhartha highway connects with one of the most important border points of IndiaNepal (Sunauli) in the south and famous histrorical places of Pokhara and Tansen in the North. Gautam Buddha airport at Bhairahawa directly connects Butwal to Kathmandu. Recently, migration from rural hills from neighboring districts to different parts of the municipality, Butwal is experiencing rapid urbanization. The population of Butwal submetropolitan city was 118,462 (CBS, 2014). The built-up area of Butwal Municipality is shown in Figure 1. 


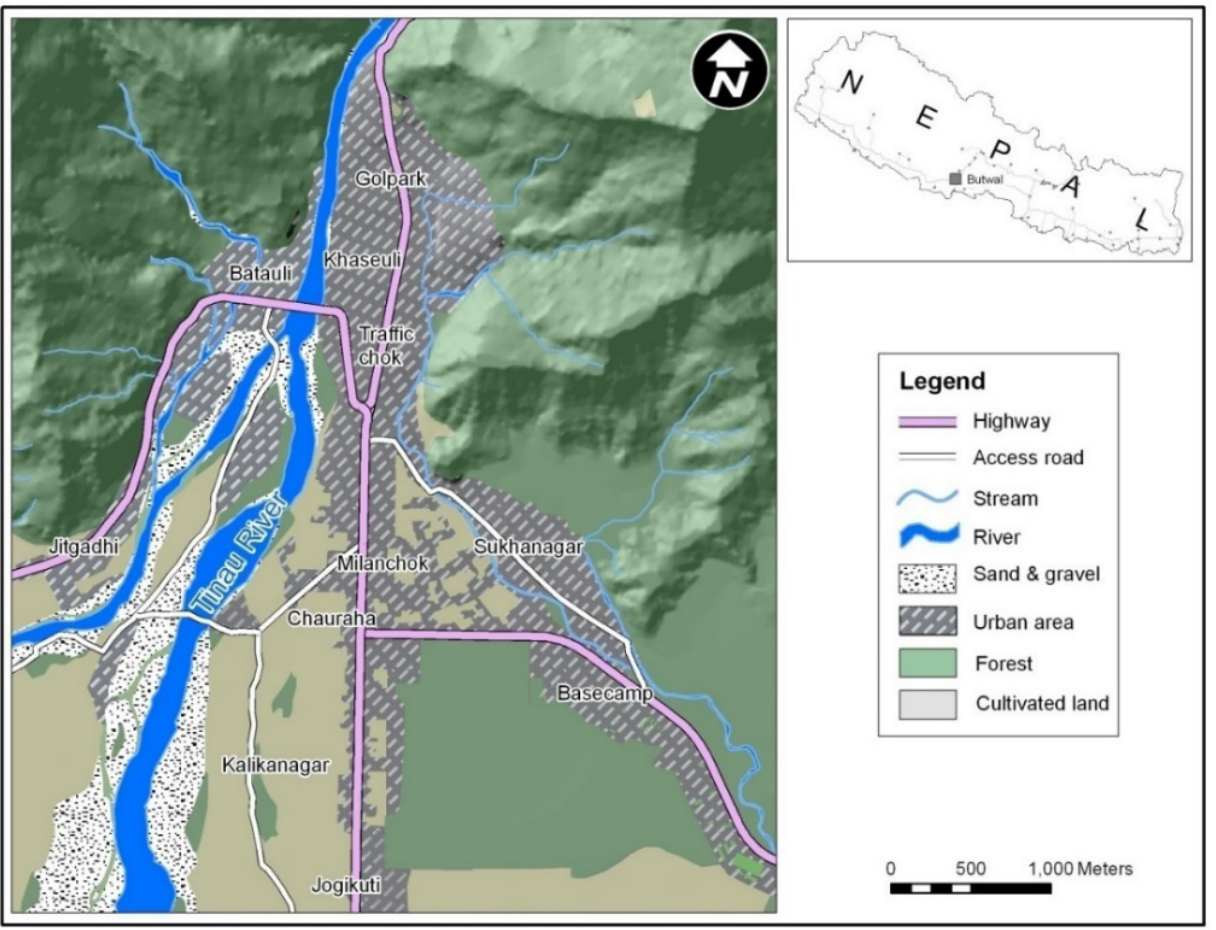

Figure 1: Study area (Butwal Bazaar)

After opening of the Siddhartha Highway, it got a tremendous progress in urbanizing process. It is now sub metropolitan city having area of 101.6 square kilometers. However, large parts of sub-metropolitan city area are rural in nature; therefore this study was executed only in the urbanized area of Butwal i.e. 15.2 square kilometers having eastwest length $4.8 \mathrm{~km}$ and north-south 5.6 kilometers.

\section{Result and Discussion}

Distribution of urban features with topographic information and concentric ring extended from the city center, land value, room rent, building storey, retailing, industrial and residential intensity have been discussed to satisfy the applicability of bid-rent theory in Butwal urban area.

Land value: Land values are higher at $\mathrm{CBD}$ and its surrounding areas. It seems similar even to the south, which is the junction of the highways. Very low land value is in the old Batauli areas, far east and far west of Butwal. The medium land values are observed in the north (Khasyauli), Sukhanagar and Kalikanagar area (Figure- 2A). Distances 
from $\mathrm{CBD}$, proximity to the highway and road access have greater influence on land value. The impact of highway is more along the north-south highway than the eastwest highway. The land value is higher at newly extended southern part than the north. Decreasing land value is along the Tinau River due to the risk factor of a flood. The impact of road access seems stronger than the distance from the CBD.

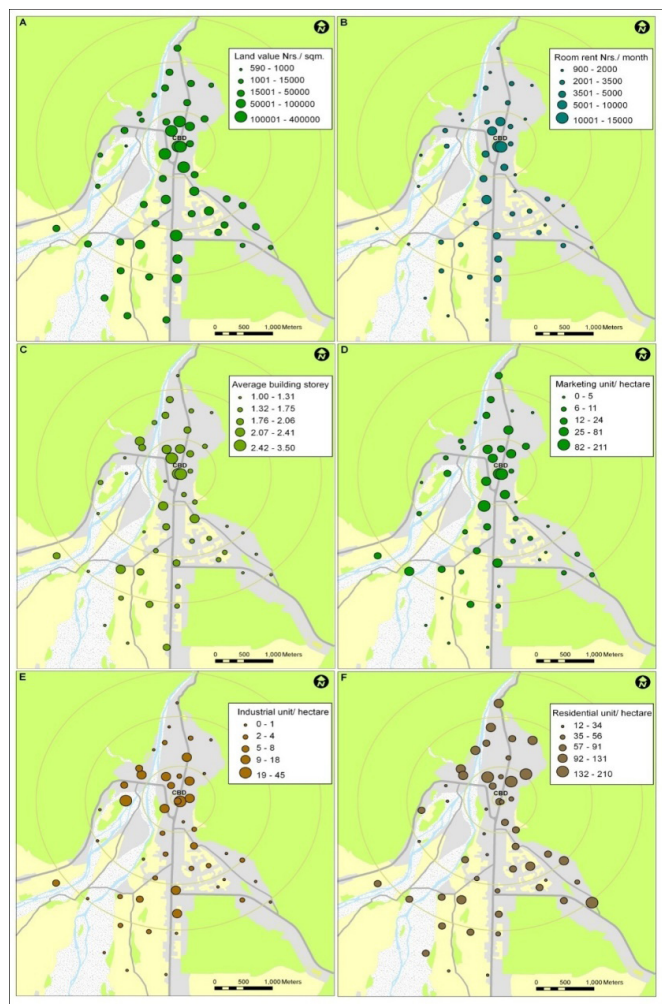

Figure 2: Urban features with concentric ring and topographic features

Room rent: The distribution pattern of room rent is more variable than land value. The highest room rent is in the CBD area and decreased beyond the area. Room rent has slightly decreased in adjoining areas of the CBD, i.e., north part and bus park area to the south. There is higher land value along the highway to the south (Figure- 2B). New extended areas like Kalikanagar, Sukhanagar and Khasyauli have lower room rent. Other area has very low room rent. Distance to CBD has the highest impact on room rent. Second, determining factor found highway and an access road. Room rent is highly different in new and old urban areas. Batauli area has very low room rent even near to the highway. It is clear that north-south highway has a greater impact than east-west highway, but greater impact seemed toward the south rather than the north. 
Building storey: Building storey is more randomly distributed than that of land value and room rent. However, it is also higher in CBD area. Second highest are toward north of CBD. Third category building storey is distributed randomly. The third category building storey is at more accessible area. Outside the built-up area, building storey observed gradually decreased which has similar trends in both old and new urban areas (Figure 2C). Distance from CBD has greater impact on the building storey rather than of accessibility.

Market function: Market function is more extensive to the outside of the CBD area. More concentration of the marketing function is at $\mathrm{CBD}$, its surrounding areas with road junctions. Urban activity is very limited outside the major urban area. The old Batauli bazaar and newly extended Kalikanagar and Sukhanagar area have very low market activities (Figure 2D). Distance from CBD and road accesses have direct impact on market activities. Major residential areas have very low urban activities, even accessibility is quite high. If we compare north-south distribution of room rent, it is somehow correlated with building storey.

Industrial function: Industrial function is more clustered in and around the CBD. It has extended opposite side of Tinau River where marketing function is very low. Another concentration is around the highway junction to the south. Lower industrial activities are along the feeder access roads to the southwest where the market function are also higher (Figure $2 \mathrm{E}$ ). Concentration of the industrial function in nearby CBD and highway junction is due to the easy access to urban area and connection to the long distance. Higher concentrations in all highway junctions are the result of high accessibility than other urban activities. Secondary road has also attracted industrial function, but the impact of highway junction is higher.

Residential units: The distribution of residential unit is in opposite of market and industrial function except some areas such as Kalikanagar, Batauli and Khasyauli area. However, northern adjoining areas of the CBD and Batauli area have a higher intensity of residential units. Sukhanagar and Kalikanagar areas have a higher intensity of residential unit where both industry and market functions are low. The southwestern corner has a higher intensity of all three (marketing, industrial and residential) intensity, but far south have higher residential intensity where industrial and marketing intensity is nominal (Figure 2F). If we compare with room rent and land value, inverse relationship existed with these factors. Therefore, it can be stated that people select cheaper land and room rent for residential use than market and industrial function. 
The distribution pattern of urban features is more concentrating on a CBD area which is natural as each urban area has its own nucleus point of the urban core (Park \& Burgess 1925). Nevertheless, complete mono-centric does not exist because highway junction and access road have also attracted urban activities (Harris \& Ullman, 1945). Physical barriers like slope and river basin (flood affected area) also played significant role in distribution of urban features (Liao, 2012). Compact settlement of old Butwal also less urban activities and more residential use like outside the major city which corroborated the study of Hollow (2011). It is due to the lack of human interaction because of lack of access to north and physical barrier. Extension of urban activities toward south indicates the urbanization process of Butwal is going to be extended southward rather than the other directions. It is because of the direct link to the Indian border and extensive open area toward the south. More urban activities towards southwest along the new access road are newly extended urban activities. The extensions of residential area, outside core are due to the choice of cheaper and open land area for residential purposes. The extension of marketing activities and residential area form core to the outside is the result of accessibility as pointed by the sector model (Pitzl, 2004). Old city area, marginal land and newly extended urban area (urban fringe) is being the choice for residential purposes. However, access to city center is also equally important for it. Therefore, the residential area is located at the place where the land value and room rent is lower which means that residential place is unprofitable, but long distance travel to the city center is also equally difficult.

Application of bid rent theory: Different land users in Butwal such as retailer, industrialist and residents in urban area compete for the most accessible land within the central business district (CBD). The bid rent curve based on the intensity of retailing, industrial and residential pattern according to the increasing distance from the city center. Traditionally, the core is the most accessible location for a large population. It requires retailing shops in a considerable turnover. Therefore, they are willing and able to pay a very high land rent value. Industrialists want to pay in the outer core where more land is available for factories, but still benefits of the inner core for market linkage and good transport links to outside of the city. Therefore, transport to the outside cities is also another important factor for industrial location (Muto, 2006).

Residential is non-commercial which cannot pay high rent and extend outside the city core. From figure 3, a scatter plot of marketing and industrial function is more linear than residential features according to increasing distance from CBD. The angle of the regression line indicates the decreasing rate of intensity of marketing from CBD to outside distance is much higher than industrial intensity. Similarly, the industrial activities decreasing intensity rate is higher than of residential intensity. So, the 
regression coefficient is the highest of marketing and the lowest of residential. These coefficients are significant at more than 99 percent of marketing and industrial but residential gradient is not significant. This situation is also in the scatter plot which is so dispersed than in a linear pattern. However, it proves that marketing function has the highest bidding capacity than of industry.

Industry is more capable to bid nearer to the CBD than residential. Residential is not so regular pattern like marketing and industrial features. However, the bid rent theory seems quite applicable even in the medium size town of developing countries.

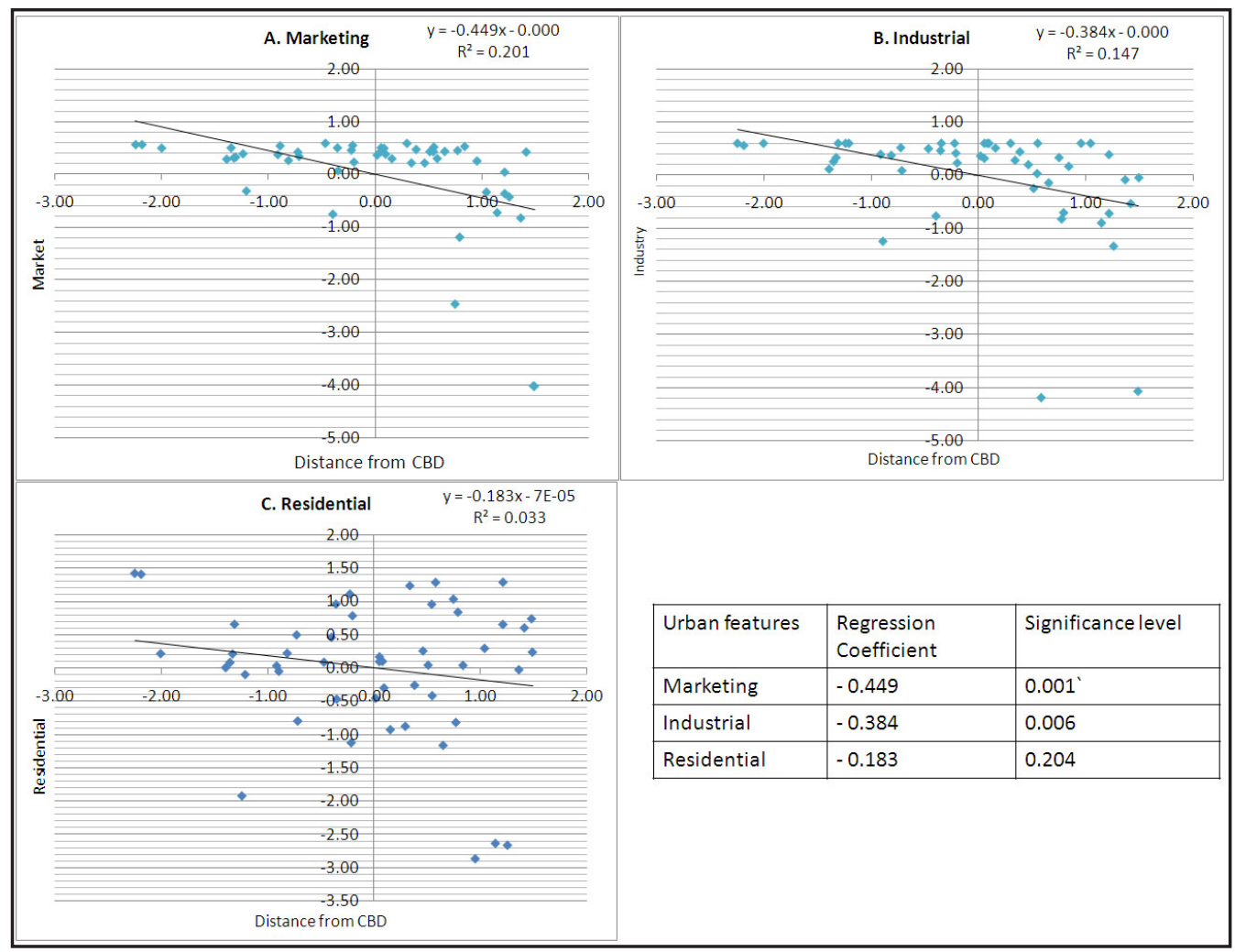

Figure 3: Scatter plot and regression line of urban features

The coefficients of determinants of marketing, industrial and residential with increasing distance from the CBD are not observed so high. The coefficient of determinants of Marketing and industrial is higher than that of residential pattern which is the similar result to regression coefficient. Very low coefficient of determinants reveals the low reliability of the intensity gradient of residential intensity from city centre to outside. So, gradient of marketing and industrial function are related to bid rent function. 
Land economics: The land use plan is intended as an important means to fulfill physical, economic, and social community goals, to maintain quality and pattern of the city's environment (Gallion \& Eisner 1984). The applicability of the urban land use in the study area is for extension of marketing and industrial function toward far south from the CBD due to highway connection to south Indian border and access road in the city. The unitization of land is ultimately determined by the relative efficiencies of various uses at different location. The process of adjustment in city structure to the most efficient land use pattern is through the competition of the uses of various locations (Ritcliff, 1949) as a result marketing and industrial functions is more intense nearby CBD. However, urban growth patterns are the result of numerous interactions among economic, political, environmental, geographic, social and cultural factors. These interactions vary with changes in population sizes of cities (Black \& Henderson, 2003). There is a strong reaction to these mechanistic explanations clearly reveals that abstraction of a limited set of economic variables form the whole complex set acting on land use is an unsatisfactory procedure as a result of mostly related economic variable is not total determinant factors of urban function and actual nature of the rent gradient in the study area.

\section{Conclusion}

Three major land use theories seem quite applicable in the study area. The intensity of most urban characters such as higher land value, room rent and marketing are at the core with decreasing intensity as distance increases form the center. This pattern is not quite a concentric pattern having higher intensity along the highway, which connects long distance to other cities as sector model. Higher intensity of the land character at the junction of major roads outside the core. The old land use theories are relevant and applicable for the land use development in Butwal. The bid-rent theory based on land economics with great emphasis on the competition among various urban functions found applicable in the study area. It indicates that land economic concept is not applicable only in big cities, but also emerging small towns of developing countries like Nepal. However, economic and social factors are not only the determinants of urban land use patterns, but physical factors like site suitability and hazard risk related factors are also play an important role to determine the pattern of urban land use in Nepalese context.

\section{References}

Alonso, W. (1964). Location and land use: toward the general theory of land rent. Cambridge: Harvard University Press.

Bakrania, S. (2015). Urbanization and urban growth in Nepal. Helpdesk Research Report. www.gsdrc.com 
Black, D. \& Henderson, V. (2003). Urban evolution in the USA. Journal of Economic Geography 3 (4):343-372.

Carter, H. (2010). The study of urban geography (Fourth edition). London: Arnold.

Central Bureau of Statistics. (CBS). (2014). National Population and Housing Census 2011: Village Development Committee and Municipality. Kathmandu: CBS.

Gallion, A. B. \& Eisner, S. (1984). The urban pattern. Delhi: CBS Publisher and Distributors.

Harris, C. D. \& Ullman E. L. (1945). The nature of cities". The Annals of the American Academy of Political and Social Science. 242: 7-17. doi: 10.2307/1026055.

Hollow, M. (2011). Suburban ideals on England's interwar council estates. Journal of the Garden History Society, 39(2): 203-217.

Liao, K. (2012). A theory on urban resilience to floods: A basis for alternative planning practices. Ecology and Society, 17(4): 48. http://dx.doi.org/10.5751/ES-05231170448.

Mayhew, S. (2006). Oxford dictionary of geography (Third edition). New Delhi: Oxford University Press.

McDonald, F. J. (2006). Urban transportation and land use. In: J. A. Richard \&McMillen, D. P. (Eds.), A Companion to urban economics. Blackwell Publishing Limited.

Muto, S. (2006). Estimation of the bid rent function with the usage decision model. Journal of Urban Economics, 60 (1): 33-49.

Ngidi, M. P. (2016). A Critical Analysis on the Applicability of Previously Established Theoretical Growth Models in Post-Apartheid South Africa: The Case of the Durban Metropolitan Area, Unpublished Master Thesis. University of KwazuluNatel.

Park, R. E. \& Burgess, E. W. (1925). The Growth of the City: An introduction to a research Project. The City, 47-62.

Putman, S. H. (1975). Urban land use and transportation models: A state-of-the-art summary. Transportation Research, 9 (2-3): 187-202.

Pitzl, G. R. (2004). Encyclopedia of Human Geography. Greenwood: Greenwood Publishing Group, U. S. A.

Ratcliff, R. V. (1949). Urban land economics. New York: Mcgraw-Hill.

Samli, A. C. (1998). Strategic marketing for success in retailing. West Port (USA): Greenwood Publishing Group. 